\title{
Erratum: Dietary Rescue of a Lethal "Null" Activity Allele of 6-Phosphogluconate Dehydrogenase in Drosophila melanogaster
}

\author{
M. Beatrice Hughes ${ }^{1}$ and John C. Lucchesi ${ }^{1}$
}

Three values were omitted from Table III (p. 475) of a previously published paper. ${ }^{2}$ The complete table reads as follows:

Table III. Pupation and Emergence of Axenically Raised $w^{a}$ l(1)Pgd- $A^{n l} / \mathrm{Y} \mathrm{Males}^{a}$

\begin{tabular}{lrcc}
\hline $\begin{array}{c}\text { Minimal media } \\
\text { supplement }\end{array}$ & \multicolumn{1}{c}{$\begin{array}{c}\text { Larvae which } \\
\text { pupated } \\
\%\end{array}$} & $\begin{array}{c}\text { Larvae which } \\
\text { produced adults } \\
(\%)\end{array}$ \\
\hline Glucose (42 mM) & 80 & - & 25 \\
Yeast (43.3 g/liter) & 101 & 72 & 41 \\
Linolenate (42 mM) & 93 & 74 & 41 \\
Fructose (42 mM) & 182 & 85 & 66 \\
\hline
\end{tabular}

${ }^{a} N$ refers to the number of third instar $w^{a} 1(1) P g d-A^{n l} / Y$ male larvae selected and followed through pupation and emergence in this experiment.

\footnotetext{
${ }^{1}$ Genetics Curriculum and Department of Zoology, University of North Carolina, Chapel Hill, North Carolina 27514.

${ }^{2}$ Hughes, M. B., and Lucchesi, J. C. (1978) Dietary rescue of a lethal "null" activity allele of 6-phosphogluconate dehydrogenase in Drosophila melanogaster. Biochem. Genet. 16:469.
} 